\title{
Serum paraproteins in chronic lymphocytic leukaemia
}

\author{
DAVID SINCLAIR, JOHN H DAGG, ${ }^{*}$ ALLAN MCI MOWAT, DELPHINE MV PARROTT, \\ DAVID I STOTT
}

From the Department of Bacteriology and Immunology and the ${ }^{*}$ Department of Medicine, Western Infirmary, Glasgow G11 6NT, Scotland

SUMMARY The presence of paraproteins in the sera of 10 patients with chronic lymphocytic leukaemia (CLL) was investigated using immunoisoelectric focusing. Monoclonal immunoglobulins were found in nine of these 10 sera. Five sera contained a single monoclonal IgM paraprotein, one serum contained a single monoclonal IgG paraprotein, while three sera contained more than one monoclonal paraprotein-namely, IgM + IgD, IgM + IgG, and IgM + IgD + IgG. The results indicate that the malignant $B$ cells of CLL may be at a later stage of differentiation than previously assumed and serum monoclonal immunoglobulin could be of value as a tumour marker.

Chronic lymphocytic leukaemia (CLL) is a disease involving malignant proliferation of a clone of $B$ lymphocytes, but the stage of differentiation of CLL cells along the continuum from $B$ lymphocyte precursor to mature plasma cell is still a matter of some controversy. Previous work has shown serum paraprotein in fewer than $10 \%$ of cases of CLL $;^{12}$ this has led to the assumption that the proliferating clone in CLL is derived from a lymphocyte as yet too immature to secrete immunoglobulin and that further maturation to immunoglobulin production does not normally occur. ${ }^{34}$

In this paper we present data on 10 patients with CLL whose sera were investigated by immunoisoelectric focusing, a technique which is highly sensitive in the detection of monoclonal immunoglobulins. ${ }^{5}$ Our results are of importance in the debate on maturity of CLL lymphocytes and suggest that monoclonal immunoglobulin could be a useful tumour marker in CLL.

\section{Material and methods}

Ten patients with CLL were studied: four men and six women, whose ages ranged from 48 to 78 years, mean 67.3 years. In each case the diagnosis was confirmed by peripheral blood lymphocytosis and bone marrow examination and the patient was allotted a stage according to the system of Rai et al. ${ }^{6}$ Details are shown in the Table. The time from diagnosis to sampling varied from one month to 13 years. Cases 2, 6, 7, 8, and 10 had received no treatment; the remainder had been treated intermittently with a combination of chlorambucil and prednisolone.

Antisera were obtained from the following sources: anti-IgG and anti-IgD from the Scottish Antibody Production Unit (Law Hospital, Carluke, Lanarkshire, UK); anti-IgM from BoehringerMannhiem; and anti- $\kappa$ and anti- $\lambda$ light chains from Dakopatts. The specificity of antisera was tested against monoclonal immunoglobulin of known isotype.

Immunoisoelectric focusing was performed as described in detail elsewhere. ${ }^{5}$ Briefly, sera were focused on agarose isoelectric focusing gels containing ampholytes which produce a $\mathrm{pH}$ gradient of 3-10 (Pharmacia Fine Chemicals, LKB). After focusing, one track was cut from the get-for example, track 4 (Fig. 1)-and placed in 10\% trichloroacetic acid to fix the proteins in the gel. The remaining tracks were overlaid with strips of cellulose acetate membrane soaked in specific antisera and incubated for $2-3 \mathrm{~h}$ at $37^{\circ} \mathrm{C}$. After fixation or incubation, the tracks were washed, dried, and stained.

Immunoelectrophoresis was performed as described previouslys using Corning Universal electrophoresis plates. Serum immunoglobulin concentrations were measured by radial immunodiffusion on plates supplied by Boehringer-Mannheim.

\section{Results}

The Table summarises the results obtained with 
Results obtained from patients with CLL

\begin{tabular}{|c|c|c|c|c|c|c|c|c|c|}
\hline Patient & Age & Sex & Stage* & $\begin{array}{l}\text { Lymphocyte } \\
\text { count } \\
\left(\times 10^{9} / l\right)\end{array}$ & $\begin{array}{l}\lg G \\
(m g / m l)\end{array}$ & $\begin{array}{l}\lg A \\
(m g / m l)\end{array}$ & $\begin{array}{l}\operatorname{lgM} \\
(m g / m l)\end{array}$ & $\begin{array}{l}\lg D \\
(m g / m l)\end{array}$ & $\begin{array}{l}\text { Monoclonal } \\
\text { immunoglobulin } \\
\text { isotype }\end{array}$ \\
\hline 1 & 69 & $\mathbf{M}$ & II & 162 & $5 \cdot 44$ & 0.25 & 0.21 & 0.042 & $\mathrm{M} \lambda, \mathrm{G} \lambda, \mathrm{D}$ \\
\hline 2 & 78 & $\mathrm{~F}$ & I & 74 & $1 \cdot 29$ & $<0.24$ & $0 \cdot 1$ & $<0.015$ & ND' + \\
\hline 3 & 55 & $\mathbf{M}$ & II & 143 & $3 \cdot 26$ & $<0.24$ & 0.56 & $<0.015$ & $\mathrm{M} \lambda, \mathrm{D}$ \\
\hline 4 & 78 & $\mathrm{~F}$ & II & 65.7 & 9.08 & 0.57 & 1.95 & $<0.015$ & $\mathrm{M}_{\kappa}, \mathrm{G} \lambda$ \\
\hline 5 & 71 & $\mathbf{F}$ & IV & $31 \cdot 4$ & $1 \cdot 29$ & $<0.24$ & 0.32 & $<0.015$ & $\mathbf{M \kappa}$ \\
\hline 6 & 68 & $F$ & 0 & $88 \cdot 5$ & 8.44 & $3 \cdot 04$ & 0.56 & $<0.015$ & $\mathbf{M \kappa}_{\kappa}$ \\
\hline 7 & 70 & $\mathrm{~F}$ & 0 & $45 \cdot 8$ & $16 \cdot 17$ & 2.07 & 0.44 & $<0.015$ & $\mathbf{M} \lambda$ \\
\hline 8 & 73 & $\mathbf{M}$ & 0 & $97 \cdot 8$ & $9 \cdot 08$ & $1 \cdot 48$ & 0.88 & $<0.015$ & $\mathbf{M} \boldsymbol{\lambda}$ \\
\hline 9 & 48 & $\mathbf{M}$ & III & 32 & 3.79 & 0.57 & $0 \cdot 21$ & $<0.015$ & $\mathrm{G} \kappa$ \\
\hline 10 & 63 & $\mathrm{~F}$ & III & 120 & $7 \cdot 82$ & 1.07 & 0.6 & $<0.015$ & $\mathbf{M} \kappa$ \\
\hline
\end{tabular}

*Staged according to Rai et al. ${ }^{6}$

†None detected.

Normal serum immunoglobulin concentrations:

$\mathrm{IgG}=5-15 \mathrm{mg} / \mathrm{ml}$

$\operatorname{IgA}=0.3-3.7 \mathrm{mg} / \mathrm{ml}$

IgM $=0.3-1.5 \mathrm{mg} / \mathrm{ml}$

IgD $=0-0.4 \mathrm{mg} / \mathrm{ml}$.

immunoisoelectric focusing from 10 patients with CLL. Of these, five had detectable serum monoclonal IgM present as solitary paraproteins, one had monoclonal IgG as a solitary paraprotein, and, interestingly, three (patients 1,3, and 4) had more than one paraprotein $(\operatorname{IgM}+\operatorname{IgG}+\operatorname{IgD} ; \operatorname{IgM}+$ IgD; IgM + IgG respectively). Only one patient had no detectable monoclonal immunoglobulin.

Fig. 1 shows the immunoisoelectric focusing patterns of serum from patient 3 . This technique clearly shows the presence of an $\operatorname{IgM}(\lambda)$ paraprotein with

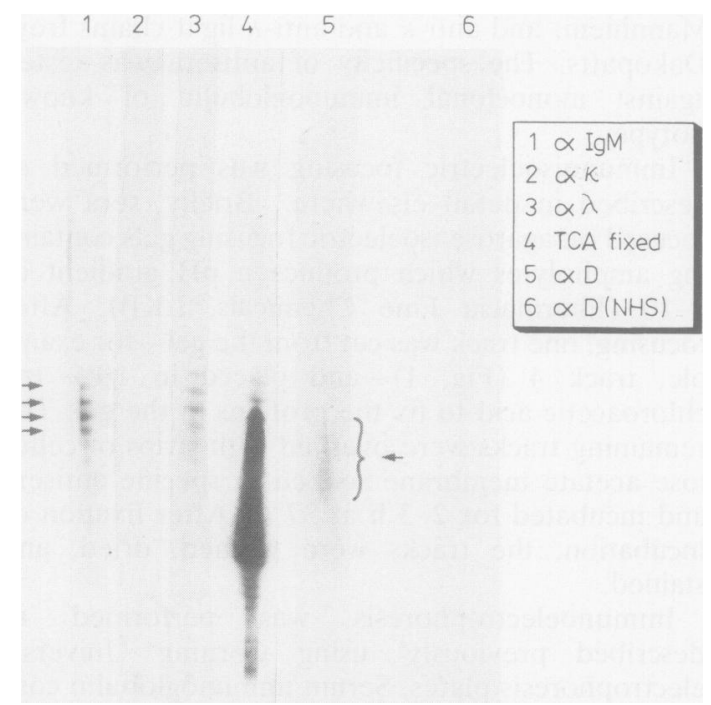

Fig. 1 Immunoisoelectric focusing pattern from a patient with chronic lymphocytic leukaemia (patient 3). Sera were focused and proteins identified by overlay of the tracks with heavy and light chain specific antisera. Arrows denote monoclonal immunoglobulin (tracks 1 and 3: $\operatorname{Ig} M(\lambda)$, track 5: $\operatorname{Ig} D)$. characteristic bands of restricted heterogeneity in tracks 1 and 3 and an IgD paraprotein with bands of restricted heterogeneity in track 5 . These bands are not found in normal human serum (track 6) because the multiple clonotypes of immunoglobulin fuse to produce a diffuse pattern with no banding present. ${ }^{5}$

With serum from patient 4 (Fig. 2) there was no detectable abnormality with immunoelectrophoresis, whereas immunoisoelectric focusing showed two monoclonal immunoglobulins, which were identified as $\operatorname{IgM}(\kappa)$ and $\operatorname{IgG}(\lambda)$ (tracks 2 and 3 and tracks 1 and 4 respectively).

Total serum immunoglobulin concentrations in the 10 patients with CLL were measured by radial immunodiffusion. In only two cases were values above the normal range (see Table): patient 4 had an IgM concentration of $1.95 \mathrm{mg} / \mathrm{ml}$ and patient 8 had an IgG concentration of $16.2 \mathrm{mg} / \mathrm{ml}$.

Immunoelectrophoresis showed no monoclonal immunoglobulin in all 10 cases studied.

\section{Discussion}

Patients with CLL and detectable serum paraproteinaemia are well documented ${ }^{7}$ but have been assumed to represent a small minority of cases, estimates ranging from $3 \%$ to $6 \% . .^{2}$ The results reported here cast considerable doubt on this conclusion as nine of 10 patients with CLL had measurable concentrations of monoclonal immunoglobulin when sufficiently sensitive techniques were used. We have shown previously that immunoisoelectric focusing is a more sensitive method for detecting serum paraproteinaemia than techniques currently in use $\mathrm{e}^{\mathrm{s}}$ and our present results indicate that the absence of monoclonal serum immunoglobulin reported in other studies of CLL is due to 


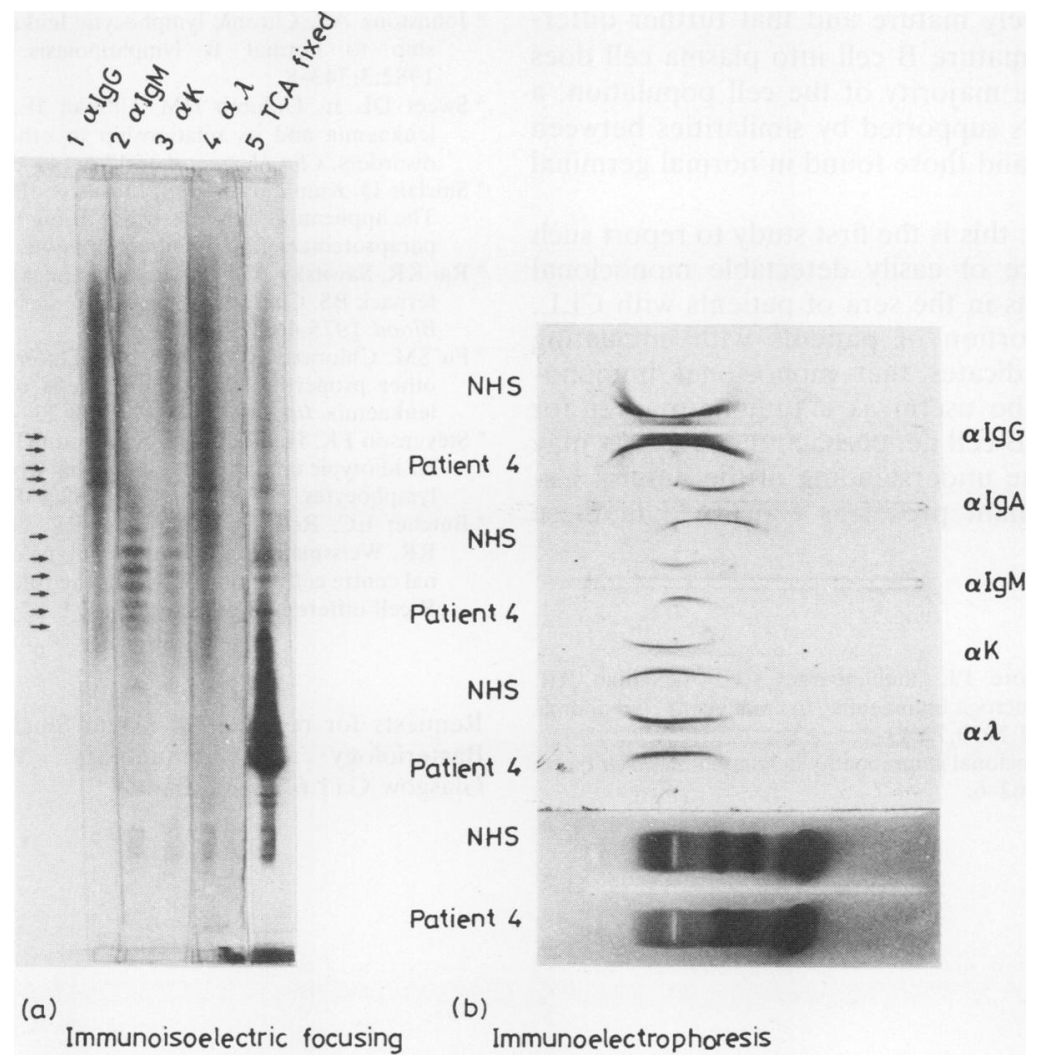

Fig. 2 Comparison of immunoisoelectric focusing and immunoelectrophoresis patterns of serum from patient 4. Sera were focused and proteins identified by overlay of the tracks with heavy and light chain specific antisera. Arrows denote monoclonal immunoglobulin, with the upper set showing monoclonal $\operatorname{Ig} G(\lambda)$ (tracks 1 and 4) and the lower set, IgM (k) (tracks 2 and 3).

insufficient sensitivity of the techniques used rather than failure of secretion by the malignant B cell clone.

In an earlier report of two patients with CLL and serum paraproteinaemia, Fu et al ${ }^{7}$ showed that the serum paraprotein, the surface IgM of the leukaemic lymphocytes, and the intracellular IgM were idiotypically identical and concluded that the serum paraprotein was the product of the malignant $B$ cell clone. We are currently investigating the idiotypic nature and source of the monoclonal immunoglobulin in our patients' sera in order to confirm this possibility.

Thus our findings indicate that serum monoclonal IgM may be a tumour marker for CLL and may prove useful in monitoring the progress and treatment of the disease. Our results may assist in resolving the controversy over the level of maturity of the neoplastic B cells in CLL. Earlier studies led to the assumption that, in general, B cells in CLL were non-secretory and were thus intermediate between pre-B cells and mature B cells. Our findings and those from earlier in vitro work $^{8}$ do not support this view and indicate that the proliferating $B$ cells are actively secreting immunoglobulin. This is supported by the finding that most of the IgM released by CLL B cells in culture is pentameric, ${ }^{8}$ whereas surface IgM shed from the cell membrane is monomeric. Also the presence of $\operatorname{IgG}$ and IgD paraproteins in three of our patients, and in a previous report, ${ }^{2}$ is consistent with the idea that at least some of the neoplastic B cells have differentiated beyond the IgM producing immature stage. The cellular source and idiotypic nature of the $\operatorname{IgG}$ and $\operatorname{IgD}$ paraproteins have not been established, however, and this will be necessary to exclude the possibility that they represent unrelated monoclonal gammopathies. We propose that in CLL the neoplastic B 
cells are relatively mature and that further differentiation from mature B cell into plasma cell does not occur in the majority of the cell population, a concept which is supported by similarities between $B$ cells in CLL and those found in normal germinal centres."

In conclusion, this is the first study to report such a high incidence of easily detectable monoclonal immunoglobulins in the sera of patients with CLL. The high proportion of patients with circulating paraproteins indicates that monoclonal immunoglobulin could be useful as a tumour marker for CLL and other B cell neoplasia and our results may contribute to the understanding of the natural history and malignant processes concerned in these diseases.

\section{References}

' Moore DF, Migliore PJ, Shullenberger CC, Alexanian RR. Monoclonal macroglobulinaemia in malignant lymphoma. Ann Intern Med 1970;72:43-7.

${ }^{2}$ Alexanian R. Monoclonal gammopathy in lymphoma. Arch Intern Med 1975; 135:62-6.
${ }^{3}$ Johnstone AP. Chronic lymphocytic leukaemia and its relationship to normal B lymphopoiesis. Immunology Today 1982;3:343-8.

4 Sweet DL Jr, Golumb HM, Ultman JE. Chronic lymphocytic leukaemia and its relationship to other lymphoproliferative disorders. Clin Haematol 1977;6:141-57.

s Sinclair D, Kumararatne DS, Forrester JB, Lamont A, Stott DI The application of isoelectric focusing to routine screening for paraproteinaemia. J Immunol Methods 1983;64:147-56.

- Rai KR, Sawitsky A, Cronkite EP, Chanana AD, Levy RN, Pasternack BS. Clinical staging of chronic lymphocytic leukaemia. Blood 1975;46:219-34.

' Fu SM, Chiorazzi N, Kunkel HG. Differentiation capacity and other properties of leukaemic cells of chronic lymphocytic leukaemia. Immunol Rev 1979;48:23-44.

${ }^{8}$ Stevenson FK, Hamblin TJ, Stevenson GT, Tutt AL. Extracellular idiotypic immunoglobulin arising from human leukaemic B lymphocytes. J Exp Med 1980;152:1484-96.

9 Butcher EC, Rouse EV, Coffman RL, Nottenburg CN, Hardy RR, Weissman IL. Surface phenotype of Peyer's patch germinal centre cells: implications for the role of germinal centres in B cell differentiation. J Immunol 1982;129:2698-707.

Requests for reprints to: David Sinclair, Department of Bacteriology and Immunology, Western Infirmary, Glasgow G11 6NT, Scotland 